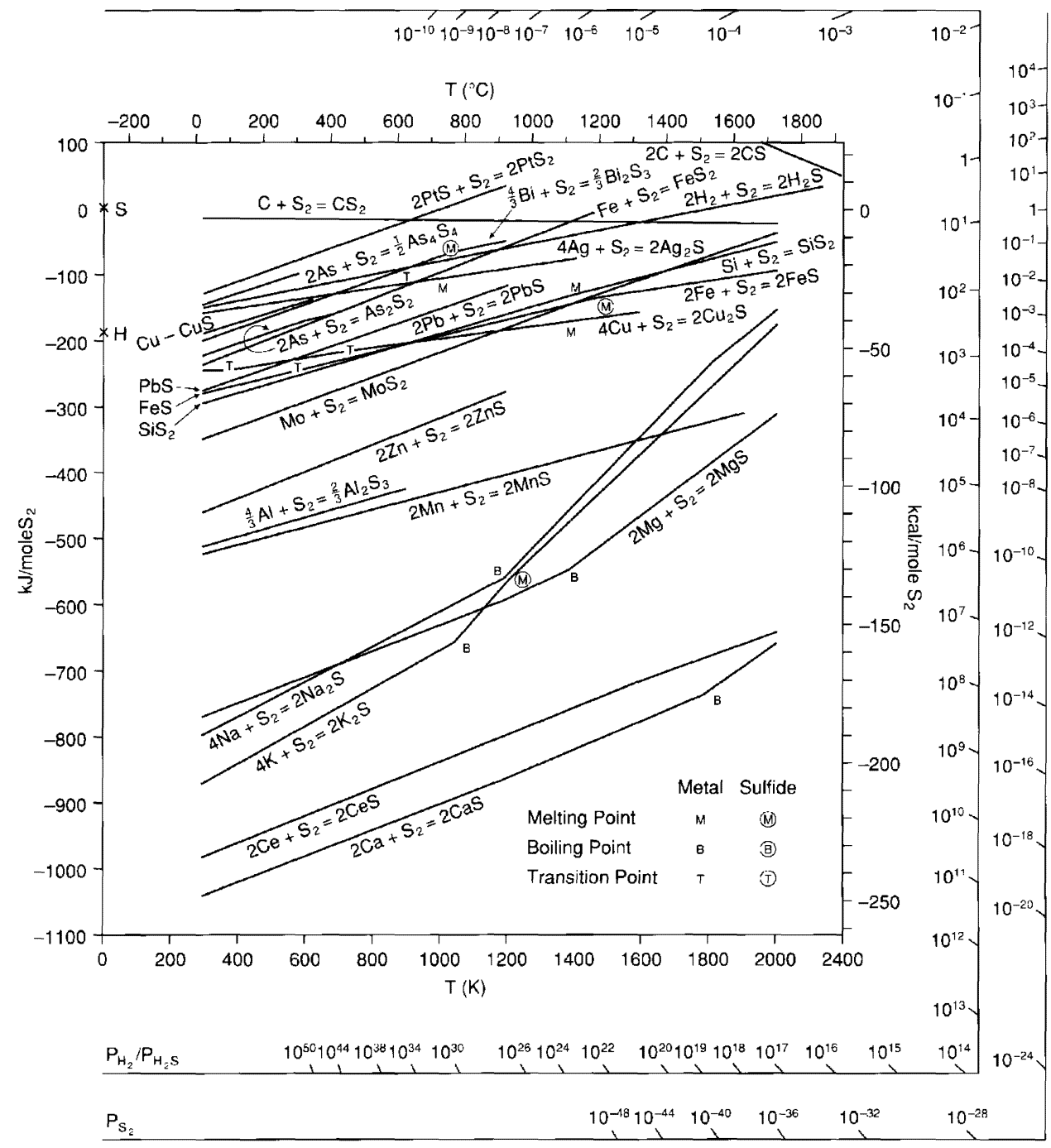


The Production
and Processing of
Inorganic Materials 


\section{The Production and Processing of Inorganic Materials}

\section{James W. Evans \\ Lutgard C. De Jonghe}

\section{Professors}

Dept. of Materials Science and Engineering

University of California, Berkeley

With a CD of thermodynamic data and

spreadsheet examples prepared by

Arthur Morris

Professor Emeritus of Metallurgical Engineering

University of Missouri, Rolla 
Authors

James W. Evans

Lutgard C. De Jonghe

ISBN 978-3-319-48566-9

ISBN 978-3-319-48163-0 (eBook)

DOI 10.1007/978-3-319-48163-0

Library of Congress Control Number: 2002109114

Chemistry and Materials Science: Professional

(C) 2016 by The Minerals, Metals, \& Materials Society

Published by Springer International Publishers, Switzerland, 2016

Reprint of the original edition published by TMS (The Minerals, Metals \& Materials

Society), 2002, 978-0-87339-541-0

This work is subject to copyright. All rights are reserved by the Publisher, whether the whole or part of the material is concerned, specifically the rights of translation, reprinting, reuse of illustrations, recitation, broadcasting, reproduction on microfilms or in any other physical way, and transmission or information storage and retrieval, electronic adaptation, computer software, or by similar or dissimilar methodology now known or hereafter developed.

The use of general descriptive names, registered names, trademarks, service marks, etc. in this publication does not imply, even in the absence of a specific statement, that such names are exempt from the relevant protective laws and regulations and therefore free for general use.

The publisher, the authors and the editors are safe to assume that the advice and information in this book are believed to be true and accurate at the date of publication. Neither the publisher nor the authors or the editors give a warranty, express or implied, with respect to the material contained herein or for any errors or omissions that may have been made.

Printed on acid-free paper

This Springer imprint is published by Springer Nature

The registered company is Springer International Publishing AG

The registered company address is: Gewerbestrasse 11, 6330 Cham, Switzerland 
To our families:

Sylvia Johnson James

Hugh

Claire

Lynn

Erika

Jessica 
The past few decades have seen the emergence of materials science (and engineering) as a discipline. The roots of that growth lay initially in the long established fields of metallurgy and ceramics and the discipline is nowadays seen as embracing these traditional fields plus electronic, optical, composite and polymeric materials, as well as biomaterials. Materials science and engineering examines materials over a large range of scales, from the nanometers of quantum dots to the meters of the steel girders used for building construction The discipline is currently growing in popularity and likely to remain so. New materials for aerospace applications, optical fibers and new applications of materials in bioengineering stir the imaginations of students and stimulate a flow of research funds.

The character of materials science is evolving as the growth continues and as scientists and engineers from other disciplines (notably physics, chemistry, chemical engineering and electrical engineering) enter the field. Nevertheless most would agree that materials science is a field at the interface between more traditional sciences and engineering fields (those listed already plus civil and mechanical engineering). It is both a scientific discipline concerned with fundamentals (in the same way as the adjacent topic of solid state physics) and an engineering subject concerned with the application of knowledge to the production and use of materials.

Another view of the field is that it has the structure of a tetrahedron with vertices labeled "Structure", "Properties", "Performance" and "Processing" and the edges representing the important interactions between these four topics. While alternative geometries have been suggested, an opinion held by many is that, until recently, the processing vertex has been neglected, at least in the USA, in favor of the other vertices. Certainly, if processing is taken to include everything from synthesis in laboratory "test tube" experiments to industrial manufacturing, then this opinion is supported by even the most casual inspection of trade figures or the business pages.

This neglect of processing has been reflected in the materials curricula at many of our universities. Courses on processing have frequently been regarded as optional or secondary and have failed to embrace the unity of materials that is recognized, for example, in other courses on fracture or characterization of microstructure. Our hope is that the production of all types of (inorganic) materials can be taught as one. Naturally there are differences between the production of a silicon nitride engine component and that of a copper wirebar but they appear to us no larger than that between producing the 
wirebar and producing a titanium ingot. In any event we claim that these differences are insignificant compared to the commonality of thermodynamics, kinetics, transport phenomena, phase equilibria and transformation, process engineering and surface chemistry on which all three rely. Naturally, those who find such integration implausible can use the book selectively, by skipping chapters on "other" materials.

This book, then, places its emphasis on fundamentals and on how those fundamentals can be applied to understand how the major inorganic materials are produced and the initial stages of their processing. These should equip the student for engineering future processes for producing materials or for studying the processing of the many less common materials not examined in this text.

This emphasis on fundamentals has posed a question. Can other texts and previous courses be relied upon to provide the necessary fundamentals for this text and a course based on it? The answer will of course depend on the students and the instructor will always have the option of skipping parts or the whole of the first few chapters. However, we argue that, because so many of the practitioners of materials science enter from different disciplines, it is wise to establish a common ground. For example, those entering from a mechanical engineering background would probably have a knowledge of chemical thermodynamics not as complete as that expected of chemists, but a considerable knowledge of process engineering. Even those from a materials science background frequently have not come across some fundamental topics important in materials processing. For example, undergraduate materials courses on diffusion seldom treat the convective mass transport that is important in the many materials processing operations where gases or liquids play a part.

Previous courses and texts encountered by the student may well have probed deeper and ranged wider into the topics of the first seven chapters but those chapters serve to emphasize what is important from those courses in terms of materials production. Selective reading of these chapters is encouraged but few will be the students who have an understanding of all the subject matter contained therein. The student who reads and grasps these chapters will be well equipped for the remaining chapters and work in the field of materials processing.

A second question we have faced is the extent to which references should be included in the text. Usually we have not included references although each chapter concludes with a list of suggested additional reading. Much of the material in this, and many other undergraduate texts, is "well known" in the sense of being scattered throughout other texts, or widely known to scientists or engineers in the field. Examples would be Fick's laws of diffusion or the statement that the electrolytic cells used to produce aluminum typically operate at $950-960^{\circ} \mathrm{C}$. Little is gained by including original references to substantiate these facts. The exception is in some of the later chapters which on occasion touch on developments that are too recent to be regarded as well known. At those points we have inserted a limited number of references, sufficient to serve as the origin for a literature survey.

We have used SI units in most cases. However, if present progress is any indication, it will be well into this century before the older units disappear, particularly in the United States. Consequently a few of the problems at the ends of the chapters have used older units.

Our intention has been to write a book suitable for a one semester (or two quarter) 
course at the Junior or Senior level. Furthermore it is hoped that graduate students, or practicing scientists or engineers, entering the field will find the book a useful introductory and reference work. This selection of the level of presentation has not been allowed to constrain our writing. Some subjects are best described using mathematics that may tax some less accomplished juniors. Indeed some of the problems have been written so as to challenge the better seniors. Conversely, other topics, for example some of the process descriptions, are so easily grasped that we have striven to avoid dwelling on them.

We emphasize the scope of the text as implied by the title. The production and primary processing of inorganic materials (ceramics, metals, silicon and some composite materials) is the subject. Although much in the first few chapters applies equally to the production of polymeric materials, their production entails topics (organic chemistry and rheology, for example) that are peculiar to them. We have therefore thought it wise to stay within the bounds of inorganic materials.

At a late stage in the production of this second edition, Arthur Morris, Professor Emeritus of Metallurgical Engineering, University of Missouri, Rolla, suggested the inclusion of a CD, to include thermodynamic data and a few Excel ${ }^{\circledR}$ based examples of how to use them. This excellent suggestion led to the CD included with this text. That CD contains files that are the thermodynamic data for approximately one hundred elements and compounds (all those encountered in the problems and more). This is a subset of the large data set FREED that is mostly the thermodynamic database of the US Bureau of Mines and is available from http://home.att.net/ thermart/ at nominal cost to students. Prof. Morris has also included on the CD some sample solutions to problems in the book, plus other problems. Some of these solutions were obtained using the software THERBAL (also available from http://home.att.net/ thermart/). Solutions obtained by such computational techniques are much more powerful instructional tools than the usual printed solutions. The student can easily change the parameters of the problem and the consequences are immediately and graphically apparent. We are greatly indebted to Art Morris

We also wish to thank Eve Edelson, who was very helpful in the preparation of the book. The late David Johnstone, editor at MacMillan, patiently steered us toward the finished manuscript that became the first edition published by that company. Stephen J. Kendall of TMS has been our aid in producing this second edition. Claire M. Evans is thanked for help in preparing the index. We would also express our appreciation to our students, who have contributed to our research and thereby to some of the body of knowledge that we have incorporated in the book. Thanks are also due to our reviewers, particularly Professors Dave Gaskell, Dennis Readey, George St. Pierre, and Nickolas Themelis for constructive criticism. We express special gratitude to our families for enduring our preoccupation with this book for a lengthy period. 


\section{Contents}

PREFACE

1 SIGNIFICANCE, HISTORY, AND SOURCES OF MATERIALS

1.1 What materials are and their importance 1

1.2 Historical summary 4

1.3 Materials at present 9

1.4 The earth as the source of materials 12

1.5 Mining 17

1.6 Mineral processing 19

1.7 Concluding remarks 27

2 CHEMICAL THERMODYNAMICS

2.1 Introduction 29

2.2 Reversibility (or otherwise) of changes 29

2.3 Entropy 31

2.4 Free energy 34

2.5 Equilibrium 37

2.6 Significance of Ellingham diagrams 58

2.7 Predominance (Pourbaix) diagrams 61

2.8 Physical equilibria 66

2.9 Concluding remarks 67 
3.1 Introduction and some definitions

3.2 Rate equations

77

3.3 Temperature effects 86

3.4 Mass transport and heterogeneous reactions

3.5 The case of the disappearing solid 99

3.6 The case of the shrinking core $\quad 100$

3.7 Concluding remarks $\quad 104$

4 POWDERS AND PARTICLES

4.1 Introduction 110

4.2 Characterization of particles 118

4.3 Characterization of agglomerates and compacts 124

4.4 Concluding remarks 129

5 SURFACES AND COLLOIDS

5.1 Significance of colloids in materials processing

5.2 Surface structure 135

5.3 Colloid interactions 146

5.4 Concluding remarks 167

6 FUNDAMENTALS OF HEAT TREATMENT AND SINTERING

6.1 Introduction $\quad 170$

6.2 Transport of matter 170

6.3 Phase equilibria 191

6.4 Kinetics of phase changes 201

6.5 Sintering: an introduction 205

6.6 Concluding remarks 207

7 PROCESS ENGINEERING

7.1 Introduction 211

7.2 Material and enthalpy balances 217

7.3 Recycles 219

7.4 Staged operations 221 
7.5 Heat balances 226

7.6 Supply of heat to unit operations 226

7.7 Process control 230

7.8 Concluding remarks 235

8 HIGH-TEMPERATURE PROCESSING FOR THE PRODUCTION OF METALS AND GLASS

8.1 Introduction 241

8.2 Thermodynamic considerations 241

8.3 Kinetic considerations and selectivity 243

8.4 Roasting 245

8.5 Reduction of oxides 252

8.6 Smelting and converting of sulfides 264

8.7 Steelmaking: preliminary refining technologies 269

8.8 Glassmaking 274

8.9 Concluding remarks 277

9 HYDROMETALLURGY AND ELECTROMETALLURGY

9.1 Introduction 281

9.2 Leaching 282

9.3 Solution purification 289

9.4 Electrometallurgy 291

9.5 Concluding remarks 316

10 REFINING, SOLIDIFICATION, AND FINISHING OF METALS

10.1 Refining and alloying of metals

321

10.2 Solidification of metals

329

10.3 Finishing operations $\quad 342$

10.4 Concluding remarks 351

11 PRODUCTION OF POWDERS

11.1 Introduction 355

11.2 Mechanical methods for powder production 355 
11.3 Production of powders from solutions 360

11.4 Production of powders by solid-solid and gas-solid reactions

11.5 Production of metal powder 376

11.6 Production of other important ceramic powders

11.7 Concluding remarks 379

12 POWDER COMPACTION

12.1 Introduction 383

12.2 Packing of particles 383

12.3 Powder compaction 388

12.4 Die compaction 390

12.5 Isostatic compaction 394

12.6 Casting methods 395

12.7 Extrusion methods 398

13 SINTERING OF POWDER COMPACTS

13.1 Introduction 402

13.2 The sintering process 403

13.3 Sintering mechanisms 406

13.4 Driving forces for sintering 406

13.5 Densification by grain boundary diffusion 418

13.6 Densification by volume diffusion 421

13.7 Creep of porous solids and the shape factor $\Phi \quad 422$

13.8 Interrelation of various transport mechanisms: sintering maps $\quad 425$

13.9 Densification of heterogeneous powder compacts: differential densification $\quad 429$

13.10 Liquid-phase sintering 433

13.11 Concluding remarks 436

14 MICROSTRUCTURE DEVELOPMENT DURING SINTERING

14.1 Introduction $\quad 440$

14.2 Grain growth 441

14.3 Pore evaluation during densification 448

14.4 Pore movement and pore breakaway 453

14.5 Concluding remarks 458 
xiv Contents

15 DENSIFICATION TECHNOLOGY

15.1 Introduction 461

15.2 Free sintering or pressureless sintering 463

15.3 Pressure assisted sintering 466

15.4 Concluding remarks 473

16 ADVANCED MATERIALS AND PROCESSES

16.1 Introduction $\quad 477$

16.2 Rapid solidification $\quad 477$

16.3 Production of silicon 480

16.4 Zone refining 486

16.5 Chemical vapor deposition 487

16.6 Preparation of composite materials from liquid metals 494

16.7 Surface modification processes 497

APPENDIX

INDEX 